\title{
Designing Relevant and Authentic Scenarios for Learning Clinical Communication in Dentistry Using the Calgary-Cambridge Approach
}

\author{
Vicki J. Skinner, Dimitra Lekkas, Tracey A. Winning, Grant C. Townsend \\ School of Dentistry, The University of Adelaide, Adelaide, Australia \\ Email: vicki.skinner@adelaide.edu.au
}

Received September $14^{\text {th }}$, 2012; revised October 17 $7^{\text {th }}$, 2012; accepted October $25^{\text {th }}, 2012$

\begin{abstract}
A clinical communication curriculum based on the principles of the Calgary-Cambridge approach was developed during the revision of the 5-year Bachelor of Dental Surgery program (BDS) at The University of Adelaide, Australia. To provide experiential learning opportunities, a simulated patient (SP) program using clinical scenarios was developed. We aimed to design the scenarios to reflect communication demands that student clinicians commonly encounter, that integrated process and content, and which students would perceive as authentic and relevant. Scenarios were based on data from focus groups with recent graduates and interviews with clinic tutors. The scenarios combined content (e.g. medical history) and process (e.g. questioning and relationship skills) at a level suitable for junior students. Students evaluated scenario-based materials and SP activities in a survey comprising Likert-scale and open-ended questions. Students rated the materials and SP activities positively; open-ended comments supported the ratings. Scenario-based materials and activities based on student-clinicians' experiences, were perceived as relevant, realistic, and useful for learning. A curriculum designed on Calgary-Cambridge principles helped address student learning needs at particular stages of their program.
\end{abstract}

Keywords: Clinical Communication Skills; Simulated Patients; Dentistry; Calgary-Cambridge

\section{Introduction}

As part of an overall revision of its five year Bachelor of Dental Surgery (BDS) program, the School of Dentistry, at The University of Adelaide, South Australia is implementing a new clinical communication curriculum in Years 1 - 3. This fits with the recognition of both the importance of patient-centred communication in health-care and the need for explicit communication teaching in health-care professions. The immediate and long-term benefits of patient-centred communication include a range of positive outcomes for patients, such as greater satisfaction with care, better diagnosis and treatment, better health outcomes, better adherence to health-care regimens, and fewer patient complaints (Little et al., 2001; Maguire \& Pitceathly, 2002; Stewart et al., 1995). Furthermore, patient-centred communication is considered a core component of best practice dental education (Sanz et al., 2008). The bodies responsible for quality assurance of dental curricula in Australia and in the UK, the Australian Dental Council (ADC), and the General Dental Council (GDC) respectively, have included communication as a major competence for dental graduates, both in its own right and for underpinning other domains of patient-centred care (ADC 2010; GDC, 2010). Our intent is that the new communication curriculum must use an accepted framework or model for clinical communication skills teaching and learning, it must include evidence-based teaching/learning methods, and it must fit the local curriculum context as well as meeting students' needs. For this study our goal was to provide authentic and relevant learning activities for Year 2 (junior) dental students.

The curriculum required a clear framework; however, the dental education literature lacks accounts of whole-program communication curricula or frameworks. Only a few dental institutions have published accounts of discrete communication modules or courses (Croft et al., 2005; Hannah, Millichamp, \& Ayers, 2004). Therefore, frameworks from medical education were considered. The common attribute of most is to link communication skills to the clinical tasks for which they are used (Kalamazoo Consensus Statement, 2001). We selected the Calgary-Cambridge approach because it is evidence-based, well-explicated, and extensive resources for curriculum planning are available (Kurtz, Silverman, \& Draper, 2005; Silverman, Kurtz, \& Draper, 2005). We then adopted its three key principles of curriculum design. First, that communication learning ought to occur in a whole curriculum, not as an isolated module, and second, that communication learning ought to be programmed vertically so that learners have recurring opportunities to revisit and extend their learning of core skills (Kurtz, Silverman, \& Draper, 2005: pp. 213-231). Finally, the Calgary-Cambridge approach addresses communication skills and clinical tasks by explicitly integrating communication process and clinical content (Kurtz, Silverman, Benson, \& Draper, 2003), which met our goal to integrate the students' clinical learning with requisite communication skills throughout the curriculum. A recent paper in dentistry, by Haak et al. (2008), described the adaptation of the Calgary-Cambridge Observation Guides to design and implement a dental communication module (Kurtz \& Silverman in Haak et al., 2008). Using a randomised controlled trial pre- and post-test design, the researchers showed that the intervention group exhibited better patient interview skills than the control group when both were rated by 
trained observers. Although the Calgary-Cambridge communication framework has medical education origins, Haak and co-authors (2008) noted its applicability to dentistry due to its inclusion of the patient examination, which is an integral part of all dental encounters.

The teaching/learning approaches in the new curriculum included sessions in Year 2 with simulated patients using formative verbal feedback, video of student performance, and checklists. Teaching and learning methods for communication skills training can include didactic teaching, observation, role-modelling, practice with simulated patients, and video-taped practice with simulated and/or real patients (Carey, Madill, \& Manogue, 2010; Maguire \& Pitceathly 2002; Rider \& Keefer, 2006). However, communication skills learning is best supported by methods requiring active involvement and immediate feedback (Maguire \& Pitceathly 2002; Rider \& Keefer, 2006), and by assessment methods that are aligned with the intended objectives of the teaching and learning program (Cegala \& Broz, 2002). The use of simulated patients is highly recommended for undergraduate learning (Croft et al., 2005; Hannah, Millichamp, \& Ayer, 2004; Rider \& Keefer, 2006) and assessment using patient feedback and dentally-relevant checklists is also advocated (Carey, Madill, \& Manogue, 2010; Theaker, Kay, \& Gill, 2000). Simulated patients used in an Englishspeaking educational setting are also useful for supporting specific target groups, such as students from diverse backgrounds or students whose primary language is not English (Chur-Hansen \& Burg, 2006).

The communication curriculum also had to fit the needs of our students and the patients they care for. As noted previously, the communication curriculum was to be embedded throughout the program to match students' developing needs as they progressed through their degree, and material was to recur vertically in different and more demanding contexts to allow students to consolidate their skills (Kurtz, Silverman, \& Draper, 2005: pp. 216-219). In the five-year Adelaide BDS program, students begin clinic experience and provide patient care from Year 1 (refer Table 1). After commencing clinic experience in the second week of their first year of dentistry, students initially provide simple preventive care for each other. In their second year, students progress to providing preventive care for family and friends who elect to attend the student clinic as patients. Then in their third year, students commence caring for patients whom are eligible for publicly funded dental care via the Adelaide Dental Hospital (ADH), which is part of the South Australian Dental Service. Year 3, 4 and 5 students, under tutor supervision, provide complete courses of comprehensive care for their patients, some of whom may be in pain or anxious, or who have been on public dental waiting lists for varying peri- ods of time.

Therefore, a particular goal of the BDS communication curriculum was to complement and augment junior students' patient care with colleagues, family, and friends to help them prepare for comprehensive hospital patient care in senior year levels. We also aimed to provide a safe setting for junior students to practise communication in preparation for comprehensive patient care. To meet these goals of integrating process and content, and longitudinally embedding and vertically spiralling communication skills into the curriculum, we implemented simulated patient activities in Year 2. The simulated patient activities built on previous clinical communication sessions in Semesters 1 to 3 of the BDS, which had comprised whole class lecture-discussion sessions and application in case-based tutorial discussions and in student clinic sessions. The aim of the project described here was to design authentic and relevant, integrated scenarios for use in simulated patient sessions and in teaching videos to support the simulated patient sessions to be implemented with junior students in 2011. The research questions were:

1) What are the communication demands of situations that our student clinicians commonly encounter when treating patients in the dental hospital?

2) What clinical situations are best suited to develop scenarios to consolidate and extend students' learning from Years 1 and 2 to Year 3?

3) Do Year 2 students perceive the scenario-based materials and activities as realistic, relevant, and useful to their development as clinicians?

In the rest of this paper we describe under Methods and Results sections headed "Scenario development" how research questions 1 and 2 were addressed. Under Methods and Results sections headed "Scenario evaluation", we show how research question 3 was addressed.

\section{Methods}

\section{Scenario Development}

The scenarios were based on research evidence of communication demands of the clinical situations that BDS students commonly experience during patient encounters in the $\mathrm{ADH}$. Therefore, to address research question 1 , a qualitative approach was used. Ethics approval was obtained to gather data through focus groups with recent BDS graduates and semi-structured interviews with clinic tutors. The recent graduates had completed their final examinations two months previously and were at the time working in the $\mathrm{ADH}$ as house dentists. Nine house dentists took part in focus group discussions. Each focus group

Table 1.

Patient care provided by students throughout the Adelaide dental program.

\begin{tabular}{cccl}
\hline Year & Semester & Clinic patients & \multicolumn{1}{c}{ Care provided } \\
\hline $1-2$ & $1-3$ & Student colleagues & Preventive care of a healthy patient \\
2 & 4 & Family \& friends & $\begin{array}{l}\text { Preventive care of patients with early oral health problems } \\
\text { Comprehensive simple course of care e.g., restorative and periodontal care }\end{array}$ \\
3 & $5-6$ & ADH ${ }^{\text {a. }}$ patients & $\begin{array}{l}\text { Comprehensive, complex course of care e.g., complex general restorative and periodontics, fixed } \\
\text { and removable prosthodontics, endodontics; medically compromised patients }\end{array}$ \\
\hline
\end{tabular}

Note: ${ }^{a}$ ADH: Adelaide Dental Hospital (patients are eligible for publicly funded dental services via the South Australian Dental Service). 
took 30 - 45 minutes and was audio-recorded. The clinic tutors were involved in supervising patient care provided by Year 3 5 BDS students in the ADH. Sixteen clinic tutors participated. Each interview took 20 - 30 minutes and was audio-recorded. The core question for the focus groups and interviews was: What situations do students commonly encounter in clinics that have presented a communication challenge for them? (i.e. research questions 1 and 2). Participants were asked to describe the features of the situations, such as precipitating factors, patient behaviours, and how these situations made the students feel. The data analysis had two objectives: to list and group the situations in order to identify a set of core types of encounters; and to describe some key features of these types of situations that could be used for scripting scenarios.

\section{Scenario Evaluation}

To address research question 3, a survey was used. Participants were Year 2 students in the 2011 cohort. Ethics approval and students' consent were obtained to match students' survey responses to the formative assessment data that were also collected during the activities (to provide immediate feedback the simulated patients, the tutors and the students all completed checklists about each encounter; students were also given a digital video file of their interaction with the simulated patient). In a class of 79 students, 67 consented to the data-matching (85\% response rate). The results of the consenting students' survey evaluations relating to students' perceptions of realism, relevance, usefulness, and impact are reported here.

The students completed a survey about the clinical communication activities after they had taken part in all the clinical communication activities using the scenarios (in videos or simulated patient role-plays). The survey comprised 15 questions: 13 Likert-scale response items and two open-ended questions. The scale items, which were rated using a 1 to 5 scale, where 1 was "strongly agree" and 5 was "strongly disagree", addressed elements of program organisation, students' perceptions of the scenarios/videos, and students' perceptions of the impact of the program. The open-ended questions asked students what aspects of the materials and activities had been most useful for their learning, and what would improve the materials and activities.

\section{Results}

\section{Scenario Development}

The focus group and interview data presented a range of situations that commonly arose in student clinics and details about the communication demands associated with them. These situations represented differing levels of complexity (from a clinical and a communication perspective) and from them we selected three core situations, which are described in detail below, from which to design the scenarios. To address research question 2, the criteria for selection were that the situation was most likely to be encountered in Year 3, the situation was appropriate to introduce in Semester 4 in Year 2, and the range of situations and scenarios would provide comprehensive experience to help Year 2 students prepare for Year 3. These scenarios provided the basis for the video scripts and the simulated patient role-play guidelines. The other, more complex situations were reserved for development into scenarios for Year $3 \mathrm{stu}-$ dents. The core situations selected for Year 2 included interact- ing with: 1) a friendly or talkative patient, because this has potential to distract the student from his or her clinical task or 2) an anxious patient, because this is quite common in dentistry, or 3) an annoyed or complaining patient, because this can permanently damage the dentist-patient relationship. The Year 2 scenarios were based on these core situations and enriched by adding detail from the data about specific aspects of patient dialogue and behaviour. For example, the recent graduates had described how patients who were anxious behaved and interacted in a number of different ways. Among these, some patients were quite frank about their dental anxiety and welcomed the opportunity to talk about it with their student clinician, while others attempted to mask their anxiety with humour or bravado.

The next step in scenario development was to integrate process and content according to the Calgary-Cambridge approach (Silverman, Kurtz, \& Draper, 2005). For each clinical situation, the aim was to identify clearly the clinical goal, then what clinical content knowledge and skills were required to achieve that goal, and what communication skills would support the accomplishment of the goal. The title of each scenario reflected the overall clinical goal, which was chosen to incorporate both the patient's and the student's needs in each type of situation; within the overarching goal we embedded specific clinical skills. The data-based scenarios were titled: "Balancing needs"; "Building confidence"; and "Defusing situations".

"Balancing needs" focuses on student-patient interaction during history-taking with a patient who is very friendly or talkative. It refers to the twin clinical goals of the situation, which are relationship-building via conversation, and focused information-gathering via the history questions. The demand on the novice student is to effectively balance the need of the patient for conversation with their own need as clinician to obtain information in an efficient and timely manner. "Building confidence" refers to the essential requirement for the student to be calm and confident when interacting with a patient who is anxious, in order to support the patient to be calm and have confidence in their student clinician so that treatment can commence. "Defusing situations" addresses the need for the student to have skill at managing their own thoughts and feelings in order to interact effectively with a patient who directs their displeasure at the student clinician. This is also to enable care to proceed. Table 2 summarises the title or core goal of each scenario, and the roles of the student and the patient in each. Table 3 illustrates the process and content skills embedded in each scenario. Table 4 shows how the materials and activities were used in student activities.

\section{Scenario Evaluation}

A large majority of students gave positive ratings to all items relating to the authenticity, usefulness, and relevance of the program and scenarios. Responses to items included: "The videos used in class seminars were realistic" $3.8 \pm 0.8$; “The videos used in class seminars helped my learning" $3.8 \pm 0.7$; “The simulated patient scenarios were relevant" $4.0 \pm 0.5$; "The simulated patient program is relevant to my future experience in clinic as a dentist" $4.1 \pm 0.7$. Figure 1 shows the number of students per rating point for each of these items. The majority of students also positively rated the impact of the program on their ability and confidence for clinical communication with patients. This was addressed by items "My ability to communicate effec- 
Table 2.

Summary of the title/core goal and the patient and student roles in each of the three scenarios.

\begin{tabular}{|c|c|c|c|}
\hline Title/goal & Summary & Simulated patient role & Student role \\
\hline Balancing needs & $\begin{array}{l}\text { Medical history with a patient who } \\
\text { is talkative \& friendly }\end{array}$ & $\begin{array}{c}\text { Talkative, asks questions, e.g. "Why are you asking me } \\
\text { that?" "Do you enjoy ...?” }\end{array}$ & $\begin{array}{l}\text { Maintaining rapport and } \\
\text { staying on track }\end{array}$ \\
\hline Building confidence & $\begin{array}{l}\text { An interview with a patient who is } \\
\text { anxious }\end{array}$ & $\begin{array}{l}\text { Openly anxious OR masks anxiety with } \\
\text { humour/bravado or delaying tactics }\end{array}$ & $\begin{array}{l}\text { Maintaining rapport \& being } \\
\text { confident }\end{array}$ \\
\hline Defusing situations & $\begin{array}{l}\text { Discussing treatment plans with a } \\
\text { patient who is annoyed }\end{array}$ & $\begin{array}{l}\text { Complains about waiting or the proposed treatment } \\
\text { plan e.g. "Why can't you do all my fillings today?" }\end{array}$ & $\begin{array}{l}\text { Maintaining rapport \& being } \\
\text { calm }\end{array}$ \\
\hline
\end{tabular}

Table 3.

Summary of the process and content skills embedded in each of the three scenarios.

\begin{tabular}{ccc}
\hline Title/goal & Process skills & Clinical content \\
\hline Balancing needs & $\begin{array}{c}\text { Patient-centred approach e.g. providing context } \\
\text { for the questions, giving clear explanations }\end{array}$ & $\begin{array}{c}\text { Medical history for dentistry knowledge: what questions are } \\
\text { asked, what follow-up questions are required } \\
\text { Building confidence }\end{array}$ \\
Refusing situations & Relationship-building e.g. acceptance, empathy & $\begin{array}{c}\text { Applying knowledge of dental anxiety; patient management } \\
\text { techniques }\end{array}$ \\
\hline
\end{tabular}

Table 4.

Student activities using the scenario-based videos and simulated patient sessions: outline provided to students.

\begin{tabular}{|c|c|c|}
\hline Session type & Session title & Session outline \\
\hline Class seminar & Introduction/Balancing needs & $\begin{array}{l}\text { Introduce aims, objectives and outcomes of activities } \\
\text { Prepare for session 1: view and discuss video example scenarios }\end{array}$ \\
\hline Tutorial 1 & Balancing needs & $\begin{array}{l}\text { A talkative patient: Commencing a } \mathrm{Hx} \text { and interacting with the patient AND staying on track, } \\
\text { obtaining required information }\end{array}$ \\
\hline Class seminar & Building confidence & $\begin{array}{l}\text { Whole-class discussion of tutorial } 1 \\
\text { Preparation for session 2: view and discuss video example scenarios }\end{array}$ \\
\hline Tutorial 2 & Building confidence & An anxious patient: Building one's own and patient's confidence before commencing examination \\
\hline Class seminar & Defusing situations & $\begin{array}{l}\text { Whole-class discussion of tutorial } 2 \\
\text { Preparation for session3: view and discuss video example scenarios }\end{array}$ \\
\hline Tutorial 3 & Defusing situations & A patient with a complaint: Managing self and patient in a potentially unpleasant situation \\
\hline
\end{tabular}

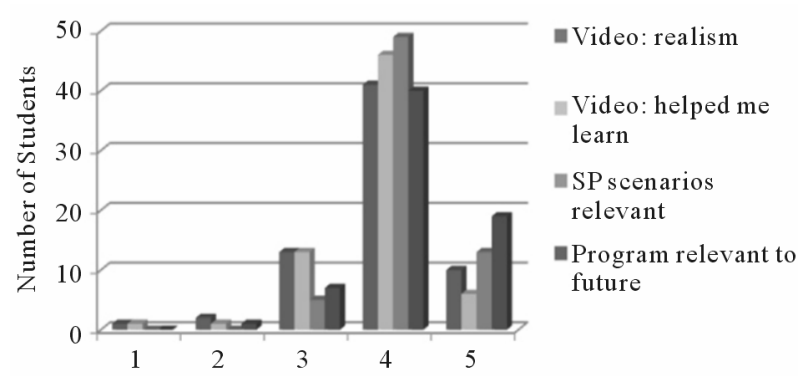

Figure 1.

Students' ratings of realism, usefulness, and relevance.

tively with patients has improved after participating in the program" $3.5 \pm 0.8$, and "I feel more confident communicating with patients after participating in the program” $3.7 \pm 0.8$. Figure 2 shows the number of students per rating point for each of these items.

The students' open-ended comments enriched and explained the positive ratings (examples of student's comments are provided in italics). A large number of comments referred to the

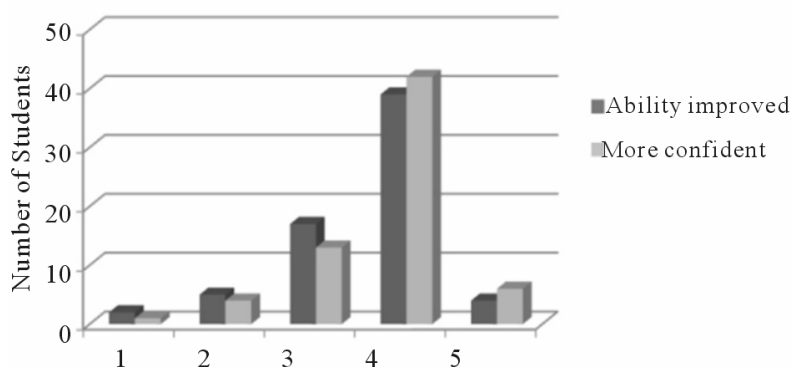

Figure 2.

Students' ratings of their ability and confidence.

videos used as a basis for class discussions in the seminars. Students said they were useful because they gave various illustrations of dentist-patient encounters in each type of situation. Students also noted that they could use or adapt these examples for their own use.

Watching videos of scenarios and discussion with class afterward-the videos were scripted so you could have a predictable, common situation, to have the 1 st exposure to patient 
communication.

Watching video examples of good patient communication: can learn good phrases \& things to avoid.

The majority of positive comments related to various aspects of the simulated patient scenarios and/or role plays with simulated patients. Students valued the opportunity to work with new and unfamiliar "patients" in addition to their familiar colleagues, family and friends. Some students also noted that this was a safe environment for communication practice and learning from errors.

Getting to interact with a stranger, a very different feeling to interacting with classmate.

We got to work with "patients" that were total strangers, definitely prepares us for further years.

Having the opportunity to communicate with real patients without the pressure.

Being able to make mistakes AND learn from them.

Students also wrote about the scenarios and their application in role plays with simulated patients. The benefit of these was two-fold: raising students' awareness of situations they may encounter in their future clinic, and providing a chance to practice interacting with patients in these situations.

Real life interactions with patient $\rightarrow$ Raised up certain issues that we were not aware of and we could discuss and make suggestions of possible ways of managing patient.

Practicing communicating answers to patient's concern: think of reasons to give patients with regards to treatment and prepares us for clinical situations.

Situations were realistic and helped me learn practical skills, a good thing to do before seeing real patients.

Gives an idea of what one can expect to encounter in clinic terms of patient expectations and reactions.

Other positive comments related to the small group format. Students noted that in addition to having their own experience, it was useful to observe and learn from colleagues' interactions. Several students identified feedback from simulated patients, tutors, and colleagues as useful for learning. There were no negative comments about the scenarios, the videos, or the simulated patient interactions. Negative comments referred to the organisational aspects of the sessions, such as altering the timing to complement other learning activities.

\section{Discussion}

Our overall goal was to develop a rationale for and then implement clinical communication activities for Year 2 dental students that would form part of a coherent communication curriculum in which process and content integrate within activities and there are recurring opportunities for students to learn (Kurtz, Silverman, \& Draper, 2005). In particular, this project sought to develop authentic, relevant scenarios for this component of the communication curriculum, and which were suitable for Year 2 students in preparation for commencing Year 3. The scenarios were used to produce teaching videos that were the basis of class discussions to prepare students for interacting with simulated patients, and to develop guidelines for the simulated patient activities. To develop scenarios, the focus group and interview data with recent graduates and clinic tutors provided rich information about actual clinical encounters and the communication demands of these situations. An obvious advantage of using data from recent graduates and clinic tutors to develop the videos was to ensure the local rele- vance of the scenarios. However, in addition, it was necessary to develop materials that were suitable for the level of the Year 2 students. While there are high quality learning materials available online about dental communication (e.g. University of Michigan open resources at

http://open.umich.edu/education/dent), the clinical content is generally too advanced or too specific for junior dental students in the BDS program.

The activities based on the scenarios were intended as part of the vertical spiral or helix structure of the curriculum (Kurtz, Silverman, \& Draper, 2005: p. 217), and to be realistic and relevant. The preliminary data from the student evaluation of the scenario-based activities show that students perceived that the activities met this curriculum goal. The majority of students were positive about the authenticity and relevance of the scenarios used in the videos and the simulated patient role-plays, and considered the activities useful preparation for their future clinic role. These active and experiential methods for learning clinical communication were recommended in a recent review of communication skills teaching and learning methods used in UK and US dental schools (Carey, Madill, \& Manogue, 2010). The students in the present study commented about the benefit of practising with strangers compared to familiar "patients", which suggests that the activities enabled them to revisit and consolidate their skills from previous communication and clinic activities in Year 1 and 2. A positive student endorsement of scenario-based video and simulated patient teaching has been reported by other dental educators. Hannah, Millichamp \& Ayers (2004) suggested that students evaluated clinical scenarios positively because they provided a "realistic and challenging learning task" (p. 975). Other studies have reported that students rate highly the value and relevance of simulated patient scenarios as preparation for their future clinic experiences (Croft et al., 2005; Gorter \& Eijkman, 1997). Comments from students in the present study suggest that a major reason for this is that scenario-based videos provided explicit strategies and language that students could adopt or adapt to practice in the role-pays, and then ultimately, in clinic with patients. The majority of students in this study perceived that their ability to communicate with patients had improved and they felt more confident about interacting with patients. Other dental education studies have shown that students felt better prepared to communicate with patients after taking part in explicit, experiential communication skills sessions (Croft et al., 2005; Hannah, Millichamp, \& Ayers, 2004; Gorter \& Eijkman, 1997).

A limitation of the present report for judging the impact of the activities is that it only contains students' perceptions. An accepted framework for evaluating the impact of educational interventions in health professions has been adapted from the Kirkpatrick system of hierarchical outcomes (Beckman \& Cook, 2007). In this hierarchy there are four ascending levels of evidence of effectiveness: 1) reaction (satisfaction); 2) learning (attitudes, skills, knowledge); 3) behaviour (impact on clinical practice); and 4) results (impact on patients). The student survey addresses the reaction and students' perceptions of learning. To adequately understand the impact of the activities, further information about the actual learning outcomes and students' behaviour in clinic with patients is required. We have data on learning, to be analysed, which includes students' written self-evaluations and the written feedback from the simulated patients and tutors. We also have written responses to examination questions that address the first two levels on Miller's (1990) 
four-level schematic (“knows”, "knows how”, “shows”, “does”) for assessing clinical skills or competence: the level of knows (knowledge of communication skills) and knows how (competence of how to apply communication skills). To be developed are ways of linking the activities to the outcomes of students' communication with patients in clinic and any resulting patient oral health improvements, i.e. Kirkpatrick's levels three and four (Beckman \& Cook, 2007), and ways of assessing these at the level of what Miller (1990) called "production": "shows" and "does". The materials and activities are being used again in 2012 as part of the communication curriculum, and further data to understand their impact are being collected.

\section{Conclusion}

The Calgary Cambridge approach provided a clear rationale for planning a communication curriculum in dentistry and then for designing activities to suit a particular niche within the curriculum. Students considered that simulated patient activities were useful for their learning needs in relation to patient communication and the transition from providing care for familiar patients, such as student colleagues, to public hospital patients who were generally strangers, were implemented. Using scenarios based on local data, students perceived the scenarios to be authentic, relevant, and useful for their learning and preparation for future clinical experiences.

\section{Acknowledgements}

The authors thank: the students and staff of the School of Dentistry; Ms Karen Squires for administrative assistance; $\mathrm{Mr}$ Corey Durward of the University Online Development Team for video production; Mr Cory Dean, BDS Hons student, for conducting focus groups and interviews (supported by a University of Adelaide Summary Vacation Research Scholarship). The simulated patient program was developed and implemented with a University of Adelaide Implementation Grant for Teaching and Learning Enhancement.

\section{REFERENCES}

Australian Dental Council (ADC) (2010). Professional attributes and competencies of the newly qualified dentist. Melbourne, VIC: Australian Dental Council (ADC).

Beckman, T., \& Cook, D. (2007). Developing scholarly projects in education: A primer for medical teachers. Medical Teacher, 29, 210-218. doi:10.1080/01421590701291469
Carey, J., Madill, A., \& Manogue, M. (2010). Communications skills in dental education: A systematic research review. European Journal of Dental Education, 14, 69-78. doi:10.1111/j.1600-0579.2009.00586.x

Cegala, D., \& Broz, S. (2002). Physician communication skills training: A review of theoretical backgrounds, objectives and skills. Medical Education, 36, 1004-1016. doi:10.1046/j.1365-2923.2002.01331.x

Chur-Hansen, A., \& Burg, F. (2006). Working with standardised patients for teaching and learning. The Clinical Teacher, 3, 220-224. doi:10.1111/j.1743-498X.2006.00128.X

Croft, P., White, A., Wiskin, C., \& Allan, T. (2005). Evaluation by dental students of a communication skills course using professional roleplayers in a UK school of dentistry. European Journal of Dental Education, 9, 2-9. doi:10.1111/j.1600-0579.2004.00349.x

General Dental Council (GDC) (2012). Preparing for practice: Dental learning outcomes for registration. London: General Dental Council (GDC). URL (last checked 30 August 2012). http://www.gdc-uk.org

Gorter, R., \& Eijkman, A. (1997). Communication skills training courses in dental education. European Journal of Dental Education, 1, 143147. doi:10.1111/j.1600-0579.1997.tb00025.X

Hannah, A., Millichamp, C., \& Ayers, K., (2004). A communication skills course for undergraduate dental students. Journal of Dental Education, 68, 970-977.

Kalamazoo Consensus Statement (2001). Essential elements of communication in medical encounters: The Kalamazoo Consensus Statement. Academic Medicine, 76, 390-393.

Kurtz, S., Silverman, J., Benson, J., \& Draper, J. (2003). Marrying content and process in clinical method teaching: Enhancing the Calgary-Cambridge guides. Academic Medicine, 78, 802-809. doi:10.1097/00001888-200308000-00011

Kurtz, S., Silverman, J., \& Draper, J. (2005). Teaching and learning communication skills in medicine (2nd ed.). Oxford: Radcliffe Publishing.

Little, P., Everitt, H., Williamson, I., Warner, G., Moore, M., Gould, C. et al. (2001). Observational study of effect of patient-centredness and positive approach on outcomes of general practice consultations. British Medical Journal, 323, 908-911. doi:10.1136/bmj.323.7318.908

Miller, G. (1990). The assessment of clinical skills/competence/performance. Academic Medicine, 65, S63-S67.

Rider, E., \& Keefer, C. (2006). Communications skills competencies: Definitions and a teaching toolbox. Medical Education, 40, 624-629. doi:10.1111/j.1365-2929.2006.02500.x

Sanz, M., Treasure, E., Van Dijk, W., Feldman, C., Groeneveld, H., Kellett, M. et al. (2008). Profile of the dentist in the oral healthcare team in countries with developed economies. European Journal of Dental Education, 12, 101-110. doi:10.1111/j.1600-0579.2007.00492.x

Silverman, J., Kurtz, S., \& Draper, J. (2005). Skills for communicating with patients (2nd ed.). Oxford: Radcliffe Publishing.

Theaker, E., Kay, E., \& Gill, S. (2000). Development and preliminary evaluation of an instrument designed to assess dental students' communication skills. British Dental Journal, 188, 40-44. 